Jan. I r. Mr. Harold Kisch, “ Nasal Obstruction."

Jan. I8. Dr. Dan McKenize, "Early Mastoid Operations."

Jan. 25. Mr. Andrew Wylie, "Tuberculosis of the Larynx."

A clinical afternoon will be held at the East London Hospital for Children, Shadwell, on Wednesday, January 2, at 4 p.m. Members of the medical profession are invited to attend without fee.

The following lectures, which are open to members of the medical profession, without fee, will be held on Thursdays, at 5.30 p.m., at the City of London Maternity Hospital, City Road, E.C. I.

Jan. Io. Mr. H. Burt-White, “'The Diagnosis and Treatment of Fotal Head Malpresentations."

Jan. I7. Mr. A. Walker, "The Treatment of Breech Presentation."

Jan. 24. Mr. J. A. Willett, "Ante-partum Hæmorrhage."

Jan. 3I. Mr. McKim McCullagh, "Postpartum Hæmorrhage."

Central London Throat, Nose and Ear Hospital, Gray's Inn Road, W.C.I :-

A course in Methods of Examination and Diagnosis will be held at the above hospital as follows: The course is free to Clinical Students, to others, fee $f$ i is.

Dec. 3r. The Ear.

Jan. 2. The Nose.

Jan. 7. Hearing Tests.

Jan. 9. The Sinuses.

Jan. 14. The Mouth and Pharynx.

Jan. I6. The Larynx.

Time I.30 p.m. Tickets obtainable from the Fellowship of Medicine.

A short course of lectures on "Functional Nervous Disorders" will be given at the Tavistock Square Clinic, 5I, Tavistock Square, W.C. I, and will begin on February II, 1929. The Fellowship of Medicine can supply syllabuses and issue tickets of admission. Fee $£^{2} 2 \mathrm{~s}$.

\section{REVIEW S.}

Aspects of Agr, Life and Disease. By Sir Humphry Rolleston, Bt., K.C.B., M.D. Kegan Paul and Co. Pp. 299. Price ros. $6 \mathrm{~d}$.

Under the skilled editorship of Dr. F. G. Crookshank, of London, and Professor R. Cruchet, of Bordeaux, a series of volumes dealing with medical and biological science are appearing simultaneously in English and French.

The present volume will add not only to the happy selection of volumes already published, but also to the fame of the author. We are accustomed to expect from the pen of Sir Humphry Rolleston deep learning, facile writing and sound common sense, all served up with a spice of subtle humour. The volume consists of a series of addresses and essays already published. Many of them are old friends, but none fails to give pleasure and profit in reading again. They range through many subjects, either medical or allied to medicine, and deal with such matters as old age, clinical variations in disease from the historical point of view, to the medical aspects of holiclays, tobacco and alcohol, truly a Lucullus feast. Every medical man who takes a holiday or sends his busy patient on holiday, will find much good reading in this chapter. Amid so much that is good it is difficult to differentiate, and the conclusion arrived at, after reading the volume from cover to cover, is that it ought to find a place on the bookshelf of every medico.

The Essentials of Medical Diagnosis. By Sir Thomas Horder, Bt., K.C.V.O., M.D., F.R.C.P., and A. E. Gow, M.D., F.K.C.P. Cassell and Co., Limited. London, 1928. Pp. $\mathbf{x x}+682$. I9 Plates. 22 Figures and 5 Charts. Price I6s. net.

This volume, which deals with medical diagnosis, fills a long-felt want. It is divided into eleven sections, the first of which describes history taking and the general principles of examination. Then follow 
nine sections, each of which is devoted to a different system of the body, and the final section is devoted to pyrexia.

In this introduction the authors refer to the lack of teaching received by the average student on the normal functions of the living human body, and at the beginning of each section is an anatomical and physiological introduction to the subject of the section which is very helpful.

An appendix at the end of the book contains tables of normal data, which includes cletails of normal cerebro-spinal fluid, digestion juices, fæces, urine and blood, amongst other useful information.

The book contains many radiograms which are well produced, and there are excellent plates of blood-films, urinary casts and different anatomical diagrams.

The section dealing with the cardiovascular system gives a very lucid description of the electrocardiograph, with diagrams of normal and pathological electrocardiograms.

On the whole the authors deal with ordinary clinical methods rather than the many laboratory tests which are in vogue at the present time.

The book is clearly written and well produced, and should prove a useful book of reference and guidance to the practitioner and student.

$\mathrm{T}$

HE Secretary of State for India proposes shortly to make a certain number of appointments to permanent commissions in His Majesty's Indian Medical Service. A Selection Board will meet at the India Office early in January to consider applications. Well qualified medical men of European descent (British subjects) who desire to be considered should apply to the Under Secretary of State for India, Military Department, India OFFICE, LoNDON, S.W.1, for forms of application, regulations and other particulars. Envelopes should be marked on top left corner "Medical Recruitment."
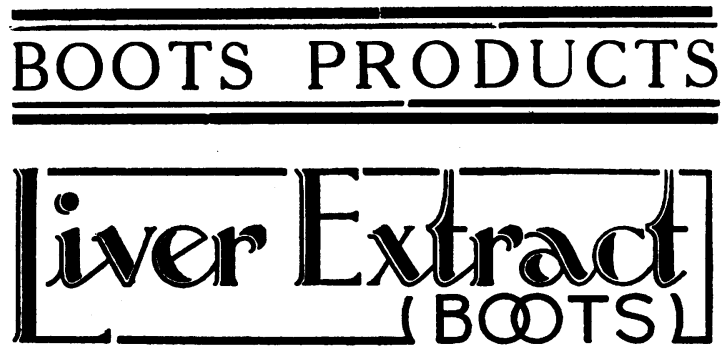

A highly concentrated extract of FRESH LIVER specially prepared for the treatment of PERNICIOUS ANAEMIA. Made by a process tested and found efficient by the Medical Research Council.

(Sec B.M.J. and LANCET, March 10th, 1928)

Supplied in yials, each equixalent to $\frac{1}{2}-1 b$. Fresh Liyer

NEW PRICES :

Single Vial - $-3 /-$

Box of Ten Vials - 30/-

Special Discounts to Medical Profession and to Hospitals.

Obtainable through all branches of Bools the Chemists

Address all enquiries to :

WHOLESALE and EXPORT DEPARTMENT

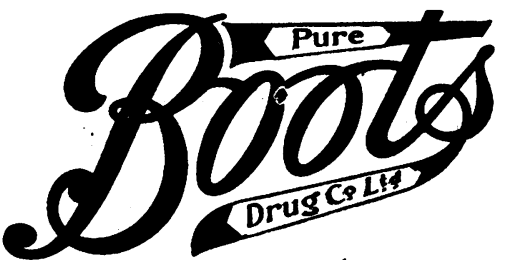

MANUFACTURING CHEMISTS MAKERS of FINE CHEMICALS NOTTINGHAM —ENGLAND

Telephone: Nottingham 45501

Telegrams : "Drug, Nottingham."

BOOTS PRODUCTS 